\title{
O papel fundante da escuta na comunicação organizacional
}

\author{
The founding role of listening \\ in organizational communication
}

El papel esencial de la escucha

en la comunicación organizacional

Marlene Branca Sólio

- Doutora em Comunicação Organizacional pela Pontifícia Universidade Católica do Rio Grande do Sul (PUC-RS)

- Mestre em Comunicação pela Universidade do Vale do Rio dos Sinos (Unisinos)

- Especialista em História Contemporânea pela Unisinos

- Especialista em Produção com Novos Meios Tecnológicos pela Universidade de Caxias do Sul (UCS)

- Graduada em Jornalismo e em Estudos Sociais pela Unisinos

- Professora-pesquisadora no curso de Comunicação da UCS

- Autora do livro Jornalismo organizacional: produção e recepção

- Editora da revista Conexão, Comunicação e Cultura, da UCS

-brancasolio@gmail.com 
Este trabalho traz a análise de entrevistas aplicadas a trabalhadores de dois grupos organizacionais para a construção de nossa tese de doutorado. A análise do discurso enfatiza princípios da psicanálise (Freud e Lacan) e da análise do discurso de linha francesa (Foucault nas questões de poder e Althusser nas de ideologia). O paradigma norteador do trabalho é o da complexidade (Morin). A análise desenha uma base sólida para a discussão da questão norteadora da pesquisa: como o comportamento dos sujeitos organizacionais, se consideramos aspectos psíquicos, vai desenhar as relações dos públicos nas organizações?

PALAVRAS-CHAVE: COMUNICAÇÃO ORGANIZACIONAL • SUJEITO • IDEOLOGIA • PODER • CULTURA

Abstract

This work offers an analysis of interviews applied to workers of two organizational groups, for the construction of our doctorate thesis. The analysis of the speech emphasizes principles of psychoanalysis (Freud and Lacan) and analysis of the French line of speech (Foucault for matters of power and Althusser for matters of ideology). The guiding paradigm of this work concerns complexity theory (Morin). The analysis outlines a solid foundation for discussion of the main issue of the research: how will the behavior of the organizational subjects, if we consider the psychological aspects, develop the relations of the publics in the organizations?

KEYWORDS: ORGANIZATIONAL COMMUNICATION • SUBJECT • IDEOLOGY • POWER • CULTURE

Resumen

Este trabajo ofrece un análisis de las entrevistas aplicadas a trabajadores de dos grupos organizacionales para la construcción de nuestra tesis doctoral. El análisis del discurso enfatiza principios del psicoanálisis (Freud y Lacan) y del análisis del discurso de la línea francesa (Foulcault en las cuestiones del poder y Althusser en las de ideología). El paradigma que guía el trabajo es el de la complejidad (Morin). El análisis dibuja una base sólida para la discusión de la cuestión que guía la investigación: Cómo el comportamiento de los sujetos organizacionales, si consideramos los aspectos psíquicos, va a trazar las relaciones de los públicos en las organizaciones.

PALABRAS CLAVE: COMUNICACIÓN ORGANIZACIONAL • SUJETO • IDEOLOGÍA • PODER • CU LTURA 
$\mathrm{N}$ a construção da tese que defendemos no Programa de Pós-Graduação em Comunicação da Pontifícia Universidade Católica do Rio Grande do Sul (PUC-RS) - Uma abordagem complexa sobre as organizações e seus sujeitos -, buscávamos perceber como acontecem os principais processos de comunicação organizacional; analisar se e como elementos de subjetividade dos atores de organizações podem interferir na recepção/interpretação/emissão de mensagens; estudar como esses processos de comunicação poderiam contribuir para a compreensão de aspectos complexos das relações interpessoais e intergrupais na organização; e propor um caminho (dentre tantos outros) que propiciasse repensar os sujeitos organizacionais e a fixidez com que são definidas e analisadas as noções de cultura/cultura organizacional, de ideologia e de poder, intimamente relacionadas entre si e desempenhando papel de sustentação de uma postura paralisante e alienadora.

A interrogação que levou à reflexão desenvolvida nessa pesquisa era: se considerarmos aspectos psíquicos, como o comportamento dos sujeito organizacionais vai desenhar as relações dos públicos nas organizações? Queríamos refletir sobre o papel dos aspectos psíquicos e de personalidade dos atores organizacionais na "leitura" que eles fazem dos apelos das organizações e das premissas de sua cultura, bem como nas respostas que oferecem A esses tópicos. Para desenhar o caminho a percorrer, recorremos ao paradigma da complexidade (Morin) e à psicanálise (Freud/Lacan), apoiando-nos, para a análise do discurso, em Foucault e Althusser (noções de poder e ideologia). Interessava-nos descobrir como as organizações poderiam modificar e melhorar os processos comunicacionais, investindo na qualificação dos processos relacionais, e se elas consideravam os aspectos psíquicos inerentes a esses

Para alcançar esses objetivos, analisamos entrevistas feitas com trabalhadores de dois grupos organizacionais. Após a leitura de cada entrevista, retomamos as categorias desenvolvidas no início da pesquisa - ideologia (para compreender as relações de poder dentro das organizações), sujeito, cultura (com interesse no aprofundamento da subcategoria de cultura organizacional) e organização -, procurando identificar pistas que confirmassem nosso problema de pesquisa e possibilitassem testar as hipóteses levantadas com relação à comunicação organizacional.

Com base na análise das falas colhidas, buscamos pistas que nos mostrassem como acontecem/são percebidos, nas organizações estudadas, os principais processos de comunicação; como elementos de subjetividade dos sujeitos organizacionais podem interferir na recepção/interpretação das mensagens; e como esses processos de comunicação poderiam enfatizar aspectos complexos das relações interpessoais e intergrupais.

A divisão dessa análise em itens estanques foi apenas didática, à medida que no discurso as noções de poder/ideologia, sujeito, comunicação, organização, ideologia, cultura e organização aparecem imbricadas, raramente na forma 
cristalina. Como falar de modo estanque em ideologia e subjetividade? Ou de poder e comunicação? Ou, ainda, de poder, cultura e organização? Assim, em muitos momentos essa aderência entre as noções em questão rompeu a divisão metodológica adotada.

O sujeito organizacional integra, concomitantemente, as esferas do social e do organizacional, sendo tocado por processos comunicacionais que se dão por meio do discurso. Parece-nos importante lembrar que, segundo Lacan (2006, p. 37), "não apenas o homem nasce na linguagem exatamente como nasce no mundo, como também nasce pela linguagem". E podemos, também, recorrer a Foucault (2002), segundo o qual temos no discurso o eco linguístico resultante da articulação entre o saber e o poder - portanto, o lugar onde se materializa a arquitetura comunicacional.

Assim, sociedade, organizações e sujeitos complementam-se, modificam-se, interagem, por meio do discurso, o qual, por sua vez gera, transforma, perpetua, renova processos comunicacionais, atualizando ideologias, que se materializam em instituições, aparelhos que regulamentam, mudam, cristalizam, alavancam relações de poder, em movimento permanente, mas nem sempre previsível e nem sempre nessa ordem.

\section{PREPARANDO 0 TERRENO}

A técnica metodológica empregada no trabalho foi a análise do discurso, especialmente o da corrente francesa, com os estudos de Althusser (1974, 1985, 2003) e Foucault $(1974,1986,1987,1997,2002)$. É importante destacar que "a análise do discurso é, com efeito, pluridisciplinar, já que, de um lado, o discurso integra as dimensões sociológicas, psicológicas, antropológicas [...] e, de outro, está no coração dessas mesmas disciplinas" (CHARAUDEAU; MAINGUENEAU, 2006, p. 15).

Com o esfacelamento da União Soviética e a grande baixa sofrida pelo comunismo, os estudos de análise do discurso sofrem reveses fortes e se revela uma tendência de agregar-lhes, cada vez mais, aspectos da psicanálise. Nesse sentido, é possível recorrer a autores como Freud e Lacan (cujos pressupostos nortearam a pesquisa no que diz respeito à psicanálise). Nossa perspectiva de análise buscou explorar as condições de produção do discurso em questão, ou seja, o contexto e, como evidenciam Moraes e Galiazzi (2007, p. 144), tiveram "como preocupação primeira a interpretação, especialmente uma interpretação crítica, fundada em alguma 'teoria forte' [...] e assumida a priori como referencial interpretativo e crítico”.

A análise do discurso busca contemplar questões nele implícitas, mais do que as explícitas, "uma vez que se preocupa com as condições de produção do discurso, com sua crítica a partir de pressupostos externos” (MORAES; 
GALIAZZI, 2007, p. 148). O oculto, o não-explicitado, foi a preocupação central da análise do discurso em nossa perspectiva de trabalho. Rosalind Gill (2005, p. 225) lembra que

os analistas de discurso, ao mesmo tempo em que analisam a maneira como a linguagem é empregada, devem também estar sensíveis àquilo que não é dito ao silêncio. Isso, por sua vez, exige uma consciência aprimorada das tendências e dos contextos sociais, políticos e culturais aos quais os textos se referem.

A autora ressalta ainda que,

quando um analista de discurso discute o contexto, ele está também produzindo uma versão, construindo o contexto como um objeto. Em outras palavras, a fala do analista de discurso não é menos construída, circunstanciada e orientada à ação que qualquer outra. O que os analistas de discurso fazem é produzir leituras de textos e contextos que estão garantidas por uma atenção cuidadosa aos detalhes e que emprestam coerência ao discurso em estudo (GILL, 2005, p. 255).

$\mathrm{Na}$ pesquisa se entrevistaram vinte ${ }^{1}$ trabalhadores em dois grupos organizacionais. As entrevistas contemplaram questões básicas e introdutórias ao tema ${ }^{2}$. Como as entrevistas foram abertas e as questões apresentaram apenas pontos de referência, no decorrer do diálogo estabeleceram-se questionamentos de maior relevância.

Parece-nos fundamental refletir sobre a especificidade da metodologia de trabalho adotada, à medida que procuramos, nos dados manifestos, o conteúdo latente ${ }^{3}$, fazendo largo uso da interpretação e da construção de um conteúdo subjetivo, que considera a dúvida. Isso não significa dizer que nos afastamos de princípios e procedimentos revestidos do que a pesquisa tradicional entende como cientificidade, à medida que, do ponto de vista epistemológico, nos amparamos em conceitos tomados de empréstimo à psicanálise.

1 Gaskell (2005, p. 71) argumenta que "há um limite máximo ao número de entrevistas que é necessário fazer e possível de analisar. Para cada pesquisador, este limite é algo entre quinze e 25 entrevistas individuais e ao redor de seis a oito discussões com grupos focais".

2 Como: motivo que o levou a escolher aquela organização para trabalhar; leitura que o sujeito faz da cultura daquela organização e como busca aplicá-la em seu cotidiano; se a organização esclarece a noção de cultura organizacional, qual é a sua cultura e que princípios compreendem essa cultura; se as relações na organização tendem à formalidade ou à informalidade; como compatibiliza seus valores e os da organização e se a organização permite/estimula esse tipo de troca; 0 que considera determinante para 0 estabelecimento das relações com seus colegas; o que espera da organização onde trabalha, como a vê e, se lhe fosse dado poder, o que modificaria nela; que conceito tem sobre a organização e sobre 0 ambiente de trabalho e que críticas faria a ela; como entende que aquela organização o percebe.

3 Como a análise se dá em profundidade e contempla, também, o latente, o não-dito, o chiste, 0 ato falho, é preciso que a transcrição seja absolutamente precisa, incluindo coloquialidades, gírias e erros de expressão. Essa consideração nos norteou nas transcrições de falas, como se verá mais adiante. 
Pela experiência adquirida nesse tipo de pesquisa, optamos por aplicar as entrevistas fora do contexto da organização. O fato de o entrevistado ter estado em seu ambiente de trabalho pode ter sido um inibidor sob vários aspectos, destacando-se a pressão de tempo para o retorno à produção e a autocensura, ou seja, o medo de que aquilo que o entrevistado viesse a dizer pudesse, de alguma forma, tornar-se público e ser usado contra ele.

Nossa vivência sugere a necessidade de o entrevistador desmitificar qualquer ideia em relação à possibilidade de sua superioridade, usando linguagem coloquial, bem como portando-se e vestindo-se com simplicidade. Parece-nos importante lembrar que,

além do poder econômico, existe o poder do "saber" que tem se tornado, através dos tempos, monopólio dos grupos dominantes. Isso não significa que os oprimidos não possuam saber, eles o possuem, mas não têm consciência do valor que este saber representa (HAGUETTE, 1992, p. 156).

As entrevistas aplicadas em nossa pesquisa foram gravadas e transcritas, tomando-se o cuidado de omitir, na transcrição, dados que personalizassem o entrevistado, bem como a empresa à qual estava ligado ${ }^{4}$. Segundo Goldenberg (1999, p. 34), "não é possível formular regras precisas sobre as técnicas utilizadas em um estudo de caso, porque cada entrevista ou observação é única: depende do tema, do pesquisador e de seus pesquisados”.

As entrevistas não tiveram limite máximo de tempo, mas, por experiências anteriores, sabíamos que demandam em média uma hora e meia de diálogo. Outro aspecto que julgamos importante foi incluir no encontro um familiar, mas que fosse também trabalhador. Essa triangulação propicia comparações, novas questões, críticas e, em algumas situações, tira o entrevistador do foco, permitindo maior descontração e uma abordagem mais profunda e "sincera" do entrevistado, que tem com seu interlocutor uma relação de intimidade e confiança. Com isso, também tivemos em mente considerar o que destaca Goldenberg (1999, p. 55).

Um dos principais problemas enfrentados na pesquisa qualitativa diz respeito à possível contaminação dos seus resultados em função da personalidade do pesquisador e de seus valores. O pesquisador interfere nas respostas do grupo ou do indivíduo que pesquisa. A melhor maneira de controlar essa interferência é ter consciência de como sua presença afeta o grupo e até que ponto esse fato pode ser minimizado ou, inclusive, analisado como dado da pesquisa.

4 Por uma questão ética, não mencionamos o nome das organizações e não traçamos um perfil delas. As entrevistas foram aplicadas em dois "grupos organizacionais", denominados A e B. No grupo A, trabaIhamos com as empresas $A$ e $A 1$ e as diferente entrevistas foram identificadas com as letras $A$ a $T$ e relacionados aos referidos grupos como $A, A 1$ ou $B$. 
A opção pela entrevista em profundidade objetiva, além da coerência com o método, considerar que "é evidente o valor da pesquisa qualitativa para estudar questões difíceis de quantificar, como sentimentos, motivações, crenças e atitudes individuais" (GOLDENBERG, 1999, p. 63). A entrevista em profundidade permite considerar reações subjetivas, o que no caso de nosso trabalho foi fundamental. Segundo Haguette (1992, p. 88), "as afirmações de natureza subjetiva estão sempre imersas em reações que devem ser levadas em conta”.

Gaskell (2005, p. 71), lembra que,

embora as experiências possam parecer únicas ao indivíduo, as representações de tais experiências não surgem das mentes individuais; em alguma medida, elas são o resultado de processos sociais. Neste ponto, representações de um tema de interesse comum, ou de pessoas em um meio social específico, são, em parte, compartilhadas. Isso pode ser visto em uma série de entrevistas. As primeiras são cheias de surpresas. As diferenças entre as narrativas são chocantes e, às vezes, ficamos imaginando se há ali algumas semelhanças. Contudo, temas comuns começam a aparecer e, progressivamente, sente-se uma confiança crescente na compreensão emergente do fenômeno. A certa altura, o pesquisador se dá conta de que não aparecerão novas surpresas ou percepções. Neste ponto de saturação do sentido, o pesquisador pode deixar seu tópicoguia para conferir sua compreensão e, se a avaliação do fenômeno é corroborada, é um sinal de que é tempo de parar.

Entendemos que a entrevista em profundidade podia trazer vantagens importantes para a pesquisa que tínhamos em vista, à medida que permite: entrevistar analfabetos; o envolvimento do entrevistado, motivando-o muito mais do que o faz a entrevista escrita; que o entrevistado repita, corrija, volte atrás e reflita ao longo da entrevista, bem como esclareça dúvidas ou lacunas; que o entrevistador faça uma leitura de expressões e gestos (linguagem corporal), bem como de atos falhos, detectando possíveis contradições (conteúdo latente); a correção de rumo da própria entrevista, pois há muitas situações em que o entrevistado traz questões ignoradas pelo entrevistador; estabelecer um vínculo entre pesquisador e pesquisado, o que leva à minimização do medo / insegurança no que diz respeito à possibilidade de uso/aplicação dos dados obtidos.

A pesquisa qualitativa exige flexibilidade e criatividade (GOLDENBERG, 1999, buscando um procedimento que lhe ofereça credibilidade. Parece-nos importante lembrar que, de modo geral, as pesquisas qualitativas derivam de estudos de campos etnográficos da antropologia e se caracterizam pela imersão do pesquisador no contexto do objeto de pesquisa, balizando-se pela perspectiva interpretativa. O pesquisador tem amplo espaço para a interpretação da realidade, com base na análise/descrição detalhada de fenômenos e comportamentos; na citação direta de experiências de sujeitos/atores entrevistados; em partes de documentos; na transcrição de entrevistas e/ou discursos (falas). A pesquisa qualitativa considera aspectos da subjetividade, ao contrário da pesquisa quantitativa, a qual trabalha com assertivas que têm 
valor de lei. Na pesquisa qualitativa, o pesquisador toma a realidade como algo da ordem do subjetivo e socialmente construído, o que leva às noções de relatividade/complexidade.

É importante ressaltar a especificidade de análise que buscamos fazer em nossa pesquisa, o que justifica apoiarmo-nos, também, na pesquisa psicanalítica, de que fala Iribarry (2003, p. 117). O autor explica que

a pesquisa psicanalítica, justamente por trabalhar com a impossibilidade de previsão do inconsciente, não poderia jamais exigir uma sistematização completa e exclusiva. [...] Ela é sempre uma apropriação do autor, que depois de pesquisar o método freudiano descobre um método seu, filiado a essa vertente, e o singulariza na realização de uma pesquisa.

Comparativamente a outros modos de abordagem, o psicanalítico não procura ou pretende estabelecer inferências generalizadoras, nem tampouco suas estratégias de análise dos resultados trabalham com o signo, mas, sim, com o significante, que está sempre aberto a novos sentidos. Como explica Caon (2002, p. 121), a "pesquisa psicanalítica deseja encontrar suas formulações essenciais na experiência, que é significante para o sujeito e desligada da antecipação prevista pelo signo”.

O pesquisador psicanalítico está implicado como um participante importante na investigação que realiza. É preciso deixar de lado, portanto, a objetividade higienizante e utópica defendida em alguns modelos de pesquisa.

Caon (2002, p. 121) sinaliza que na pesquisa psicanalítica

o campo será o inconsciente; o objeto será o enfoque ou a perspectiva a partir de uma posição em que é colocado o pesquisador psicanalítico com o fim de aceder ao inconsciente; e o método será o procedimento pelo qual ele se movimenta pelas vias ou perspectivas de acesso ao inconsciente.

Para Iribarry (2003, p. 122), "a situação psicanalítica de pesquisa (SPP) tem fundamentação na situação psicanalítica de tratamento (SPT). A transferência é a característica identificatória da SPP a partir do modelo da SPT. ”A situação psicanalítica de pesquisa irá desembocar em um texto metapsicológico, enquanto a situação psicanalítica de tratamento se dissolve. No que Caon (1996) chama de leitura-escuta, o psicanalista escuta apoiado na teoria e, por outro lado, fica atento ao desfile de significantes que os analisantes (no caso de nossa pesquisa, vinte entrevistados que integravam a quadro funcional de três organizações ligadas a dois grupos empresariais) realizam com sua fala.

O pesquisador psicanalítico se movimenta por meio das suas impressões transferenciais sobre o texto examinado e fica atento ao desfile de significantes que o tecem. Segundo Pierre Fédida (apud IRIBARRY, 2003, p. 127), 
essas impressões transferenciais resultam do modo como o pesquisador faz sua leitura dos dados, o que faz com que surja a pergunta: mas, então, o pesquisador psicanalítico é movido por sua subjetividade ao analisar o dado de pesquisa? Sim, esta é a contribuição mais legítima que podemos extrair do percurso de Freud, pois este sempre esteve movido por suas inclinações pessoais diante dos dados de sua pesquisa, e foi graças à sua interferência subjetiva que a psicanálise nasceu como uma teoria, um método e uma técnica de tratamento.

\section{Caon (2002, p. 117) chama de transferência instrumentalizada}

o processo por meio do qual o pesquisador se dirige ao dado de pesquisa situado pelo texto dos colaboradores e relaciona seus achados com a literatura trabalhada e procura, além disso, elaborar impressões que reúnem as suas expectativas diante do problema de pesquisa e as impressões dos participantes que forneceram suas contribuições na forma de dados coletados.

Frisamos, assim, que a abordagem adotada em nossa pesquisa considerou os aspectos de subjetividade do entrevistador e olhou para a inter-relação entrevistador/ entrevistado como um processo - portanto, dinâmico e complexo.

Momento importante de nossa pesquisa foi o da análise criteriosa dos dados obtidos por meio das entrevistas gravadas, comparando-os e cotejando os resultados com a fundamentação teórica levantada em pesquisa bibliográfica e com as reflexões dela consequentes, para, então, confirmar ou repensar nossas questões de pesquisa ${ }^{5}$. É importante trazer para a discussão a questão da neutralidade / objetividade tanto do entrevistador quanto do quadro de entrevistados. Para isso, recorremos a Haguette (1992, p. 87) quando diz:

Não acreditamos que o real possa ser captado "como um espelho", ao contrário, assumimos a postura relativista, de cunho weberiano, de que fazemos "leituras" do real. Esta postura, entretanto, não exime de dedicar atenção a todas as possíveis limitações inerentes ao método científico nas ciências sociais, porque nos parece que é a partir da aceitação de cada limite do método que o cientista social pode ter a condição, também, de entender os limites do dado que ele colhe do real.

\section{QUANDO TUDO FALA}

Acreditamos que estarão trabalhando com possibilidades ampliadas de sucesso aquelas organizações que otimizam seus processos de escuta. Estas fazem

5 É importante frisar que em nosso trabalho se pretendia um olhar transdisciplinar. Assim, sua essência estava em buscar, em disciplinas como a psicanálise e em áreas como a análise do discurso, uma contribuição sólida para a comunicação organizacional. Não se trata aqui, portanto, de buscar uma revisão sobre o que já foi ampla e competentemente desenvolvido na disciplina da comunicação organizacional interna. 
uma leitura em profundidade de formas de comunicação como a troca de informações convencional (diálogo), o silêncio, a formalidade, informalidade e espontaneidade no relacionamento interpessoal/intergrupal, o ato falho, o chiste. Consideram o medo, as doenças laborais, o absenteísmo, a rotatividade, as defesas criadas, quer pelo grupo, quer pelo sujeito, as transferências de setor, as incoerências, o estado de espírito das diferentes equipes, as fofocas e os boatos e o leiaute do ambiente. São alguns dentre outros fatores, o que leva a uma análise complexa.

Muitos dos aspectos que acabamos de mencionar compõem estatísticas das organizações, mas seus resultados não consideram a subjetividade e os processos de computação/análise, que raras vezes são interpretativos. Em grande número de casos, não existe um cruzamento/relação de dados, os quais são vistos de forma dissociada do conjunto daquele ambiente. Justificou a entrevista F:

"A gente acha que isso não seria muito confiável [pesquisa qualitativa], porque, se eu tenho um problema com o meu chefe, à medida que eu falo isso claramente, eu não sei até que ponto eu posso ser bem ou mal interpretado."

Isso deixa à mostra a falta de confiança do trabalhador na relação com a organização: "Se eu respondo uma pesquisa e eu não me identifico e ninguém pode me identificar, eu posso ser mais fiel", argumenta, sem considerar que o anonimato também pode acolher a má-fé e a distorção. "Então, nós usamos mais a ouvidoria, no sentido de, assim, 'eu tô mal com o meu chefe, eu posso procurar, tu me ouve, eu te ouço' e tudo mais.”

Em primeiro lugar, é posta na berlinda, até como mecanismo de defesa, a relação chefia/subordinado, o que pode ser indicativo de ponto nevrálgico na organização, se pensamos no processo de livre associação da psicanálise, pois, ao falar sobre o assunto, foi isso que veio à tona na memória/fala do entrevistado. Em segundo lugar, se a ouvidoria é acionada, o processo para a pesquisa qualitativa teoricamente estaria aberto. E, em terceiro lugar, ao justificar que "fazer pesquisa perguntando para as pessoas as perguntas que a gente faz na pesquisa de clima, a gente acha que não seriam respondidas", a entrevista mostrou o desconhecimento do que seja uma pesquisa qualitativa. É importante salientar que não estamos dispensando o uso da pesquisa quantitativa. O que evidenciamos é a ausência da pesquisa qualitativa.

De outro lado, a entrevista $S$ nos deu pistas em outra direção ao responder à questão sobre se, hoje em dia, ainda resiste uma relação de medo entre o funcionário com a empresa?

"As pessoas calam para não perder o seu emprego. Porque, com certeza, nós teríamos muito para falar, se não fosse este medo. Mas vai do teu dia também, porque tem dias que tu não está de bom humor e sai alguma coisa sem querer". 
A entrevista evidenciou a necessidade de olharmos para a subjetividade na relação com o sujeito, quando trouxe à tona a latência do recalcado e o medo de que ele possa se precipitar.

A entrevista $\mathrm{O}$ mostrou o tipo de leitura que a recepção faz da pesquisa quantitativa, o que vem de encontro ao que foi dito na entrevista F:

"Eles fazem a pesquisa de satisfação. Mas é obscura esta pesquisa. Quando eles veem que não está bem para eles, eles não dão bola, eles querem ver o que apontam para se levar a sério. E em vez de arrumar o que foi pedido, eles ignoram a pesquisa. Eles sonegam os defeitos da empresa".

Está clara, na fala, a polifonia do discurso. Muitos comportamentos organizacionais evidenciam a operação de processos emocionais inconscientes, quer estejamos nos referindo a indivíduos ou a grupos. Esses comportamentos podem impedir que a racionalidade, caminho normalmente apontado para a consecução de metas organizacionais, nos ofereça uma resposta/solução. Há líderes que sustentam ameaça velada ou deixam clara sua necessidade de estar permanentemente no controle. Muitos deles, para se sustentar em suas posições, precisam da ansiedade de seus seguidores. A entrevista $\mathrm{C}$ evidenciou isso:

"É mais fácil ele [o gerente] falar conosco do que nós irmos falar com ele. [...] Ele sempre deixa aberto pra quem quiser ir falar com ele, independentemente de assunto ou não, mas a maioria das pessoas não vai. E por quê, tu achas? Receio, eu acho, porque ele só mostra cara feia. Por um lado, ele tem a porta aberta; do outro, ele tem a cara feia."

Por outro lado, há grupos que não aceitam bem a divisão de problemas organizacionais. Exigem um líder carismático, que afaste suas (deles) ansiedades/ problemas. Compartilhar a busca de soluções e desvelar problemas representa para esse tipo de grupo semear insegurança no ambiente de trabalho. À medida que a sintonia entre líder/liderados se fortalece, as opiniões do líder são acolhidas e os liderados tenderão a transferir para a organização a afetividade / confiança nele depositada. Paralelamente, as ansiedades dos seguidores tenderão a ser transferidas para o líder, o que pode levar ao enfraquecimento de sua energia. Além disso, executivos com comportamento paranoide, depressivo ou esquizoide colaboram para a instalação de sentimentos de desconfiança, pessimismo e insegurança.

Normalmente, líderes com personalidade autoritária são conhecidos pelo alto nível de irracionalidade e pela dificuldade em admitir seus erros, bem como pela recusa a aceitar advertências / contestações. Esse tipo de liderança, muito comum, vai de encontro ao que prega Eugène Enriquez (1997, p. 79): quanto mais uma instituição é viva, percebe suas contradições internas, se coloca indagações, é capaz de uma abertura, cede seu lugar ao imaginário-motor ${ }^{6}$, é

6 Para ver a oposição imaginário-motor/imaginário enganador, consultar Enriquez (1997). 
trabalhada pela reflexão e pela reflexidade, tanto mais ela mantém no interior de si mesma o movimento instituinte e menos se arrisca a cair no instituído, quer dizer, na inércia e na repetição; todavia, ela não pode funcionar assim, se não aceitar a condição de ser atravessada pelo social histórico e, por conseguinte, pela luta pelo poder e pelo conflito das ideologias.

Um questão das entrevistas era: "Em algumas organizações, o poder se dava por imposição. Vomo tu vês isso? Existe ainda dentro da tua organização?” O entrevistado A respondeu com ênfase:

"Existe. Existe. As pessoas aqui de dentro da fábrica trazem esta cultura de 1980, do início dos anos 1990: o chefe é aquele que manda e o colaborador é aquele que respeita, baixa a cabeça e faz, e não abre a boca. Porém, todo mundo sabe, ou pelo menos deveria saber, que hoje em dia isso não funciona mais. O colaborador não deve ser apenas o executor. Ele tem que ser um executor com senso crítico. Tem que ser do tipo: "Eu faço assim, porém se eu fizer assim vou ter mais utilidade e posso reduzir meu trabalho em tempo". Então eu vou lá dizer pro meu chefe que eu devo fazer assim. Existem chefes que absorvem isso como oportunidade de melhoria, e tem pessoas que dizem: "Não! Faz o teu trabalho e cala a boca, porque você é pago para fazer e não para pensar". Infelizmente, existe isso.”

Isso dá ideia de uma realidade distante do que Enriquez apregoa como ideal. Olhar para o conflito como modo natural de regulação do grupo poderia canalizar energias para a solução desses mesmos conflitos. Temos, portanto, que a racionalidade é um mito e que emoção e conhecimento estão interligados.

Comportamento autoritário, retaliação e falta de flexibilidade no diálogo são muito comuns em organizações. Alguns dos depoimentos colhidos mostraram isso com exatidão. "Olha, no meu setor está mudando, [no sentido de piorar] por causa que antes, com o nosso chefe antigo, nós tínhamos um apoio, muito melhor motivação", relatou a entrevista C, fazendo eco à fala de diversos dos trabalhadores entrevistados, que reproduziram o mesmo acontecimento. Referindo-se ainda ao supervisor demitido, C enfatizou: "Ele já estava no caminho de preparar nós, mas só que com um jeitinho." A fala que segue desenha o ambiente organizacional:

"Hoje pra tu ir num médico, tu tem que passar pelo médico da empresa pra poder pegar um atestado, pra poder fazer um exame, pra poder consultar. Depois, tu volta, a empresa vai avaliar se vai pegar teu atestado ou não, sabe? Está terrivel. Não dá nem pra ficar doente. Se depender da empresa, a gente mora lá dentro."

Em oposição, na entrevista $\mathrm{D}$, ouvimos, com relação à outra empresa estudada nessa pesquisa:

"As empresas [grupo] preparam seus líderes e gestores, não só como gestores de negócios, mas como líderes de pessoas. Elas se preocupam não só com a seleção dessas pessoas, mas com o desenvolvimento delas." 
Um dos fortes gargalos na relação liderança/subordinados, adequadamente apontado por Enriquez ${ }^{7}$, aparece em diversas entrevistas obtidas na pesquisa. Destacamos um trecho de uma delas. Referindo-se à metodologia denominada coach, o entrevistado A disse:

"É um trabalho bastante interessante, onde nós podemos observar um monte das carências, das dificuldades que o pessoal tem na relação horizontal, vertical tanto pra cima quanto pra baixo e frutos desse trabalho, muito poucos, infelizmente devido à postura de alguns gerentes, pelo feedback que tivemos do pessoal, não na [nome da organização], principalmente mais na [organização]. O pessoal ficava [dizendo]: - Ah! Os chefes pedem isso, mas na prática é diferente. Poxa, o pessoal vai lá e faz um treinamento que diz que você tem que ser afetivo, valorizar a autoestima do outro... De repente, vai um lá e diz que se deve levar em consideração a autoestima do outro, uma atitude mais afetiva, e no outro dia vai lá o chefe [...] só na porrada. Dai não dá, né?"

Atitudes, leituras/interpretações, desvios/ruídos atravessam decisões/intenções das organizações, às vezes partindo de um ator na direção do(s) grupo(s), outras partindo do grupo na direção de um ator. As relações são dinâmicas e sofrem metamorfoses, donde a necessidade do olhar acurado para as subjetividades/especificidades.

Um das organizações estudadas tem um programa de integração entre alta(s) liderança(s) e produção: "Jantar com o presidente". E a outra está implantando um programa na mesma linha. Outros programas desse tipo, disseminados principalmente a partir da década de 1980, como "Café da manhã com o presidente" ou "Portas abertas" (inaugurado, no Brasil, pela Rhodia, em 1985), têm sido implantados e enterrados há cerca de três décadas, justamente pela falta de sintonia entre a valorização do trabalho braçal em relação ao trabalho intelectual. Ao ser solicitado a falar sobre a relação do alto escalão com os demais trabalhadores, A destacou:

"Chega a ser uma faca de dois gumes. Na maioria das vezes é o constrangimento que impera. Muitos chegam e falam o que gostam e o que não gostam, mas temem a demissão, uma represália, uma série de coisas. Daí, neste jantar, o [nome do presidente] acaba tomando a palavra e acaba agradecendo, pois quem na verdade sua pela empresa são os seus empregados. Então, acaba virando tudo, pois ele devia estar ali pra ouvir, não pra falar. [...] O cara que vaza metal fundido, ou a menina que rebarba lá na [organização A], não vão falar nunca. E isso mostra a cultura da empresa. Já o administrativo fala mais".

7 Logo que alguns aspiram à mudança e querem viver de modo diferente, outros se arvoram em arautos do conservadorismo e das necessidades da ordem social. Quando o inconsciente (ou a história) fala, o mito e a estrutura respondem. Logo que a transgressão ameaça, que o recalcado retorna, as forças de recalque e de repressão retomam seus direitos e adquirem uma nova virulência. A organização desconfia do inconsciente e da luta de classes, ela é habitada pelo fantasma do uno do qual os dirigentes são fiadores e os encenadores. Eles sabem muito bem que, se deixarem as pulsões se pronunciarem muito, que, se trouxerem à cena histórica o recalcado ou o excluído, perderão seu poder e suas razões de ser (ENRIQUEZ, 1997, p. 290). 
Prestar atenção ao recalcado que emerge sob a forma de ato falho ou pela própria denegação resulta em informações de grande valor para a análise das relações. Podemos destacar alguns exemplos que viersm à tona de forma muito clara na entrevista B. "É um ambiente agradável, produtivo, como toda empresa". E prossegue: "É bastante apertado, tem um acúmulo muito grande de máquinas, pouco lugar dentro para circular e bastante abafado". Na mesma entrevista, ao mesmo tempo em que fala da autoridade (querendo referir-se a autonomia) do operador, o entrevistado disse: "Na parte que eu comando.".Logo em seguida, explica de que forma é feita a cobrança de responsabilidades/tarefas: "Toda segunda-feira tem uma reunião com os dois supervisores e as pessoas-chave, que tocam a fábrica", o que pode levar a pensar em gerenciamento participativo. A frase seguinte, porém - "Inclusive o setor de [...] no qual o supervisor pega uma pessoa que ele acha importante ver na reunião"-, revela a efetiva centralidade de poder. Mais adiante, ao longo da entrevista, ele reafirmou: "Esta parte de autonomia, sim, embora com limites. Nos últimos seis meses, a gente tem comprometido mais os operadores. As soluções devem partir deles mais do que de mim". Isso mostra, nos parece, quão unilateral é o que o entrevistado chama de autonomia. Pouco depois, o mesmo entrevistado, ao falar do sistema de contratação/ promoções, dentro da organização, cometeu mais um ato falho, que neste caso mostrava a disputa de poder: "Porque, infelizmente, por mais que tu não queira, existem as pessoas que se destacam um pouco mais dentro do setor e que daqui a pouco vão ser preferidas para a vaga". Em um primeiro momento, poderíamos fazer um esforço para compreender a afirmação no sentido de que o entrevistado gostaria de que todos tivessem as possibilidades de conquista da vaga. Mas não é conveniente esquecer que "todo sujeito que engaja seu discurso no curto-circuito da falação faz necessariamente ouvir muito mais do que ele crê dizer" (DOR, 1985, p. 154) (grifo no original do autor).

Parece-nos clara a importância de se atentar à polifonia dos discursos, aos textos que se depositam nas dobras do texto, formando, mais do que pregas, verdadeiros bolsões de conteúdo latente, farto material para pensarmos os processos comunicacionais nas organizações. Olhar de forma acurada para as relações grupo/indivíduo, indivíduo/grupo, grupo/grupo e indivíduo/indivíduo nos parece um dos caminhos para a sintonia entre organizações e sociedade, em uma relação de fortalecimento de ambas.

\section{O JOGO DO PODER}

O homem é um ser social. Agrupar-se, inicialmente como forma de sobrevivência, levou à complexificação/organização das relações, o que implica normas, regras, leis, obediência/desobediência, hierarquia, disputa de liderança e poder. O "primitivo" foi, paulatinamente, desenvolvendo processos de produção/tecnologias, aprendendo a recalcar seus instintos, a lidar com frustrações/sentimentos de culpa/remorso, desenvolvendo processos de civilização e culturas. A civilização recalcou instintos primitivos como o canibalismo, o incesto e a ânsia de matar, mas 
há incontáveis pessoas civilizadas que se recusam a cometer assassinato ou a praticar o incesto, mas que não se negam a satisfazer sua avareza, seus impulsos agressivos ou seus desejos sexuais, e que não hesitam em prejudicar outras pessoas por meio da mentira, da fraude e da calúnia, desde que possam permanecer impunes; isso, indubitavelmente, foi sempre assim através de muitas épocas da civilização (FREUD, 1974, p. 23).

Relação implica, portanto, disputa de poder, quer estejamos falando de sujeitos, quer de grupos. E parece importante pontuar que esse processo contará, também, com as competências, mais ou menos desenvolvidas, de cada sujeito em particular. Freud (1974, p. 18) lembra que "só através da influência de indivíduos que possam fornecer um exemplo e a quem reconheçam como líderes, as massas podem ser induzidas a efetuar o trabalho e a suportar as renúncias de que a existência depende”. E Enriquez (1997, p. 98) ressalta que o sujeito,

quando não chegar a resolver os seus problemas, conhecerá a tentação de achar um bode expiatório que não tenha nenhuma responsabilidade na situação presente ou que se revele como a pessoa mais frágil, por esse fato, a única que o grupo pode sacrificar alegremente no altar de seus problemas porquanto ninguém a teme.

Em uma das entrevistas desenvolvidas na pesquisa, ouvimos declarações que mostram como funciona o jogo de poder, como os sujeitos se percebem em vantagem/desvantagem e como traçam estratégias. A entrevista B disse que "as empresas de menor porte permitem ao funcionário uma relação afetiva muito maior e uma identidade mais ampla. Os funcionários de empresas maiores têm a sua identidade apagada, neste sentido", o que confirma nossa hipótese de que as organizações dificilmente dão ouvidos a/valorizam seus sujeitos. E o entrevistado continuava, em plena sintonia com o que afirmamos até aqui: "A multiplicidade de egos inflados é muito grande. Então, as relações são complicadas", o que dá ideia, também, de quão acirrada é a disputa de poder. O mesmo entrevistado ressaltou a questão do sofrimento no trabalho, ao dizer que

"nas empresas pequenas, a tendência é aumentar a informalidade e com ela crescem as relações afetivas. Mas, nas grandes, conheço muitos que ganham bem, e sofrem, dizem que gostam, da boca pra fora, mas o único interesse deles é o dinheiro, sem compromisso."

Os trabalhadores levantaram questões fundantes no que diz respeito à relação que a organização estabelece com eles, no sentido de fazerem-nos iludir-se sobre o que, de fato, recebem:

"As grandes empresas de automóveis apagam a identidade do funcionário fora da organização, mas dão a ele uma identidade que tem a cara delas dentro dos portões da fábrica. E elas, na verdade, tratam muito bem seus funcionários e elas tiram o couro dos montadores. Esses é que são realmente os explorados pelas montadoras." 
Ainda na entrevista $B$, ouvimos que

"a relação com o empregado não é pelo coração. Ele veste a camisa da empresa, assim, não sendo uma relação pelo afeto, mas uma relação pelo bolso. Porque a empresa oferece a eles [funcionários] determinadas vantagens financeiras que outras não oferecem, ou seja, vantagens financeiras indiretas".

A disputa pelo poder acontece em várias instâncias, simultaneamente. Em muitos casos, testemunhamos uma "queda de braço" entre áreas/setores/grupos. Vejamos, por exemplo, o que respondeu o entrevistado A à pergunta sobre se "a organização apaga a identidade das pessoas da equipe de trabalho":

"Nós tínhamos um supervisor que fazia a contratação; ao invés de ser o RH era por ele. [...] Fazia questão de contratar pessoas submissas, que não abriam a boca. [...] O cara tímido é que para ele era o bom; o cara que falava bastante não tinha chances. Ele tirava a identidade da pessoa antes mesmo de ela entrar. Então, quando ela entra, ela não abre a boca, não fala 'bom dia!', não diz nada. Só que tem pessoas que passavam [no sentido de ludibriar o entrevistador] por essa triagem. E é interessante que tem sempre alguém que sabe manipular ele também. E é interessante que tu vê pessoas lá dentro que são críticas, e isso é bom. É bom ter algumas pessoas que digam o que está bom e o que está ruim. Se ninguém abrir a boca não se veem os problemas. Quem vê o problema é quem tá lá manipulando, fundindo, alisando a peça.'

Na sequência, o entrevistado trouxe à tona a questão da polifonia dos discursos dentro de uma organização, por conta da subjetividade de seus sujeitos. $\mathrm{Na}$ contramão do comportamento evidenciado, ele destacou:

"[Os dois supervisores de meu setor] têm um perfil bastante parecido comigo. Porque na verdade uma forma boa de tu administrar é transparência no que tu fala. Se tu não está contente com a pessoa, chama ela, faz uma reunião ou pode ser até um bate-papo de corredor, uma conversa aberta".

Dizermos, portanto, que a organização em questão tem perfil A ou perfil B seria perigoso. O que podemos dizer, então? Que a preocupação com a subjetividade de seus sujeitos traria à tona, nas organizações, incoerências como a evidenciada comparando-se as duas entrevistas.

A divisão do trabalho aparece sob formas diversas: remuneração, autonomia, ambiente e discurso, entre outros aspectos, sinalizam "o lugar de quem é pago para produzir e o de quem é pago para pensar". [...] "Pessoas é um negócio dificil de lidar; principalmente quando se trata com pessoas que têm niveis diferentes de conhecimento e de cultura", disse o entrevistado B. "O grande pulo que nós precisamos dar é, sim, pegar nossas metas de empresa, de companhia e transformar na linguagem na qual a turma de baixo vai entender." A fala estabelece o lugar de quem pensa e o lugar de quem executa: "a turma lá de baixo" deve produzir, a de cima, pensar. 
"É uma coisa, quando tu precisa que a turma de baixo entenda suas metas e objetivos, tem que falar na linguagem deles." A entrevista levantou, ainda, a questão da falta de escuta das organizações, as quais normalmente não conhecem a gramática de seus atores, empregando, por via de regra, a delas.

A fala do entrevistado B mostrou como é possível dosar formalidade/informalidade, autoridade/respeito/autonomia:

"Temos um pouco de formalidade tanto em cima quanto embaixo. Por exemplo, métodos, hoje, são formais, pois não estão só na cabeça das pessoas. Informalidade: dar um puxãozinho de orelha no cara, e funciona. Jamais, se alguém erra, vai tomar uma carraspana na frente de todo mundo. Tem uma linha muito tênue entre ser autoritário e ter autoridade, sem grosseria. Tem muitas empresas onde o autoritarismo ainda funciona."

A metáfora do lugar, que desenha relações de poder, também traz à tona questões de ideologia. Ela dá conta do que diz Althusser (2003, p. 102-103), quando escreve que a ideologia funciona como um espelho duplo, sendo que essa estrutura especular garante

a interpelação dos indivíduos como sujeitos; sua submissão ao sujeito; o reconhecimento mútuo entre os sujeitos e o sujeito, e entre os próprios sujeitos, bem como o reconhecimento de cada sujeito por si mesmo; que tudo está bem assim, e sob a condição de que, se os sujeitos reconhecerem o que são e se conduzirem de acordo, tudo estará bem.

Nesse quadro teremos que o sujeito é, então, produtor e produto do cenário no qual está inserido - como reza o princípio da retroatividade -, livre para ser submisso - como diz Althusser. Podemos fazer essa leitura ao analisar algumas das respostas da entrevista $\mathrm{D}$. Comentamos sobre a decisão da organização em proibir seus trabalhadores de participarem de atividades sindicais, mantendo, até mesmo, vigilância nesse sentido. À questão "mas tu não achas que a pessoa deveria ter este direito? É contrasenso, não é verdade?”, ouvimos: como resposta "De certa forma sim, é um contrassenso". Pense-se no princípio da liberdade de ir e vir, calculando que em pleno século XXI, de certa forma, não vemos sentido na expressão. Continuou o entrevistado:

"Mas isso hoje ainda permanece, não mudou. Nós estamos vivendo um momento em que [...] em Caxias e região o sindicato tem uma atuação muito forte, e isso volta a ameaçar as empresas. Existe uma pressão e uma vigilância sobre as pessoas, mas é que eu vejo que os sindicatos também têm fugido da sua finalidade".

O embate de forças e a disputa de poder são, nos parece, inerentes ao processo civilizatório, como já vimos em Freud. Assim, podemos pensar que, como defendemos o direito de o ator organizacional inserir-se no movimento sindical, a organização pode defender-se dele. O que nos preocupa é analisar as distorções impressas ao discurso no sentido de resultar no autoconvencimen- 
to. Em um primeiro momento, ouvimos o argumento: "Eu vejo que o sindicato tem servido de instrumento para alavancar as pessoas numa carreira política, e aí as pessoas usam o sindicato para se promover, eu vejo isso também. Não só para o interesse dos trabalhadores." Desconhecer a aderência/sintonia entre política e sindicalismo nos parece, no mínimo, ingênuo. E, ao contra-argumentarmos, encontramos nova tentativa:

"O problema é quando as pessoas usam o sindicato para se promoverem. É usar o sindicato, é mobilizar uma classe trabalhadora contra as empresas, para se autopromover, para na próxima eleição se candidatar a um cargo político, enfim. É pegar e distorcer algumas coisas também. Isso é o que o sindicato faz. Eles destorcem algumas realidades para ter seu lado político."

O discurso, montado sobre "palavras guarda-chuva", espécie de fórmula, se desmonta em seguida: Mas a organização também faz isso, e nós sabemos que ela faz. Não é verdade? "É" (risos).

A veemência, a repetição, a força e a sobredeterminação são recursos que variam em precedência e intensidade, mas que são invariavelmente utilizados para interpelar o indivíduo como sujeito, convencendo-o de que tudo esteve sempre assim e é como deve permanecer. E ficam o medo, a insegurança, a incerteza, a dúvida.

"Eles não reconhecem o teu trabalho, e ainda querem que você dê o que você não pode. Está sendo muito estressante trabalhar. [...] Porque dai eles cobram assim: que a gente tem que produzir sem ter perdas. Só que dai a gente faz o possivel pra não ter estas perdas, mas só que às vezes não é nosso problema da [setor], e sim falha nos processos, que dão essas perdas. Faz anos que não dá lucro o PPR, mas eles sempre estão em obras fazendo galpões novos, mas dizem que é dinheiro de empréstimo, mas nunca mostram os papéis pra nós. E dai não temos como dizer se isso é dinheiro do PPR ou se é verdadeiramente dinheiro de empréstimo. Mas como nós somos minoria perto dos maiores... Dai a gente acaba se fechando."

\section{QUANDO SE TRATA DO SUJEITO}

Em “O mal-estar na civilização”, Freud (1974, cap. V) discute, entre outras questões vitais para a psicanálise, a do princípio do prazer versus o princípio da realidade, o que significa pensar em prazer e sofrimento, felicidade e infelicidade. Esse nos parece um viés importante para refletir sobre a questão do sofrimento/satisfação no trabalho. Em determinado estágio, o autor nos diz que

nenhuma outra técnica para a conduta da vida prende o indivíduo tão firmemente à realidade quanto a ênfase concedida ao trabalho, pois este, pelo menos, fornece-lhe um lugar seguro numa parte da realidade, na comunidade humana. A possibilidade que essa técnica oferece de deslocar uma grande 
quantidade de componentes libidinais, sejam eles narcísicos, agressivos ou mesmo eróticos, para o trabalhador profissional, e para os relacionamentos humanos a ele vinculados, empresta-lhe um valor que de maneira alguma está em segundo plano quanto ao de que goza como algo indispensável à preservação e justificação da existência em sociedade. A atividade profissional constitui fonte de satisfação especial, se for livremente escolhida, isso é, se, por meio de sublimação, tornar possível o uso de inclinações existentes, de impulsos instintivos persistentes ou constitucionalmente reforçados. No entanto, como caminho para a felicidade, o trabalho não é altamente prezado pelos homens. Não se esforçam em relação a ele como o fazem em relação a outras possibilidades de satisfação. A grande maioria das pessoas só trabalha sob a pressão da necessidade, e essa natural aversão humana ao trabalho suscita problemas sociais extremamente difíceis (FREUD, 1974, p. 99).

A afirmação de Freud nos leva a refletir sobre o sofrimento no trabalho, condição que já analisamos com o testemunho de Dejours $(2005,2006)$. Na mesma medida em que pode ser fonte de prazer, o trabalho pode ser também fonte de dor e sofrimento, tanto se analisarmos aspectos psíquicos quanto se analisarmos aspectos relacionados ao ambiente físico considerando, entre outros elementos, a ergonomia e a insalubridade.

Um dos entrevistados (B) destaca, logo após afirmar que o ambiente de trabalho é agradável:

"Estamos agora num divisor de águas, porque a gente vai ter um prédio novo com uma malha maior, um ambiente mais amplo que vai ser melhor do que já era. O atual é bastante apertado, tem um acúmulo muito grande de máquinas, pouco lugar dentro para circular e bastante abafado."

Situações de desvalorização, desprestígio e mesmo desprezo são comuns no ambiente de trabalho. Assim como a internalização, pelo trabalhador, do conceito de que ser "bonzinho", quietinho, não incomodar define o bom trabalhador, premissa que encontra reforço nos uso dos aparelhos ideológicos e nos aparelhos de repressão de que fala Althusser (2003). E também em Lacan, quando diz que o sujeito está destinado a um lugar antes mesmo de nascer, pois uma ordem significante anterior a ele estabelece um sistema de relações e ele não é outra coisa senão o efeito desse sistema estabelecido pelo outro. O sujeito, portanto, advém na sua enunciação "O sujeito, não na medida em que faz o discurso, mas em que é feito por ele, é o sujeito da enunciação" (LACAN, 2006, p. 45).

Quando o trabalho, teoricamente fonte de prazer e realização, aparece associado a condenação, a luta, a suor, a estresse total, a fator impeditivo de crescimento intelectual, fica impossível vinculá-lo ao princípio do prazer, na mesma medida em que é fácil ligá-lo ao princípio da realidade e à pulsão de morte. $\mathrm{Na}$ entrevista $\mathrm{C}$ ouve-se: 
"Moro sozinha, esta casa é alugada. Tudo que tem aqui foi com a conquista do meu trabalho. A casa é assim pelo meu suor, pela minha luta. [...] Hoje eu tenho que dar prioridade: ou comprar minhas coisas ou estudar. Eu tenho só segundo grau e hoje eu sei que não vale mais nada ter apenas o segundo grau. Tem tantos cursinhos ai que a gente poderia estar fazendo."

Aqui parece oportuno recorrer a Freud (1974, p. 136), quando fala que o homem é naturalmente agressivo e tende a explorar seu semelhante. Ele aponta a solução para essa questão, ao dizer que "é sempre possível unir um considerável número de pessoas no amor, enquanto sobrarem outras pessoas para receberem as manifestações de sua agressividade". Sem ter lido o autor, ou refletido amparada nos ensinamentos psicanalíticos, a entrevistada D fez coro ao ensinamento, quando respondeu à questão "Vocês todos iriam no limite e fariam tudo que eles estão exigindo, só que sem estresse, bem tranquilos, se tivesse um ambiente mais humano?"

"Eu acho que sim, porque a gente dava conta; com o antigo encarregado, a gente dava, até porque ele sentava e trabalhava junto conosco. Ele nos incentivava e a gente conseguia. Hoje, é só na cobrança. Não que não se consiga, né, mas se consegue com muito mais estresse. As meninas lá que eu vejo estão superestressadas. Os supervisores vão ver de meia em meia hora o quanto foi produzido, e isto se torna chato e, queira ou não, eles estão exigindo; eles tentam passar que tu tem que trabalhar normal. Dai colocaram uma fichinha assim, com o código da peça, e tu tem que fazer tanto por hora. E se tu não faz? Ele diz que tu tem que trabalhar normal. mas tem que produzir o que está no papel."

Em contrapartida, ouvimos na entrevista A:

"Agora, minha função é muito mais interpessoal do que técnica. [...] Esta área é muito mais dificil [...], é um desafio, pois, na técnica, ou tu sabe ou tu não sabe. Nas relações interpessoais, você tem que trabalhar todo dia e aprender com cada pessoa, você tem que saber como trabalhar com cada um, para poder obter sucesso. É algo que eu estou aprendendo no dia a dia, ainda. É algo que me interessa".

Transparecem, mais uma vez, dois aspectos fundantes para uma organização: a importância de se olhar para a subjetividade do trabalhador e a importância de a organização ter uma escuta para perceber distorções como a que fica evidente quanto ao modo de estabelecer relações - ou seja, uma liderança que, com seu poder, gera um clima de sofrimento e ansiedade e outra que, com o mesmo poder, busca um ambiente de harmonia pela redução do sofrimento.

Como Morin explica temos o circuito risco/precaução, o circuito fins/meios e o circuito ação/contexto. No primeiro, "para toda ação empreendida em

8 Em outro momento, um entrevistado falou de um mecanismo criado no mesmo grupo empresarial, para 0 controle da produção. A cada peça trabalhada o empregado deve acionar um botão que vai registrando a produção. 
meio incerto, existe contradição entre o princípio do risco e o princípio da precaução, sendo um e outro necessários" (MORIN, 2001b, p. 88). Muitas das medidas de formalidade nas organizações são estabelecidas para evitar riscos, como forma de precaução para que sejam previsíveis. "Não é absolutamente certo que a pureza dos meios conduza aos fins desejados, nem que sua impureza seja necessariamente nefasta” (MORIN 2001a, p. 88).

Assim, ensina Morin, os processos relacionais não podem ser submetidos a leis objetivas; devem considerar a presença/autonomia/independência/competência do outro. A cada mensagem corresponderão múltiplas interpretações/respostas/pontos de fuga, o que por si desmonta a pretensão unívoca e equivocada do formal. Em alguns casos, ao sobrepor-se à comunicação formal, a informalidade exerce papel importante na organização, corrigindo possíveis falhas / distorções e/ ou fazendo com que a comunicação atinja seus objetivos, o que de outro modo não aconteceria. Na entrevista B com uma liderança de fábrica, apareceu mais uma vez o discurso do respeito às subjetividades/individualidade:

"A gente precisa respeitar a individualidade das pessoas. Porém, utilizar delas o que elas veem de melhor. Por exemplo: não adianta eu pegar uma pessoa que é "toco de enchente" e colocar num lugar onde eu preciso de um empreendedor, e vice-versa. Não adianta eu ter um cara extremamente meticuloso e colocar ele a trabalhar numa linha de produção, onde ele tem que tocar peça. Não adianta eu ter um cara ambicioso no lugar onde ele não vai ter muita atribuição [...] Mas, ainda existe nas organizações, em geral, aquela coisa de 'eu vou fazer isso, mas só e porque, se alguém vier fazer isso aqui, vai pegar meu lugar'. [Quem é] gestor nunca pode ter medo de perder o emprego, porque alguém vai pegar seu lugar."

Esse olhar acurado que encontramos na entrevista $\mathrm{B}$, a valorização das individualidades e o respeito às competências específicas, é destronado em outro ponto da fábrica, quando se ouve, de C:

"Eu acho que é exigência da própria gerência. Eu não sei se pela empresa. Eles não explicam pra nós, pelo menos é o que eu acho. Por que [...] a gente só vê lá, tem que produzir e produzir, que nós temos que fazer a empresa dar lucro e lucro. E com os funcionários não estão nem aí, se os mesmos estão cansados, estressados, contentes com o que estão realizando. Eles só veem o lado da empresa."

\section{O FIO QUE TECE A CULTURA}

As diversas entrevistas aplicadas ao longo da pesquisa nos trouxeram uma surpresa no que diz respeito à noção de cultura organizacional. Pudemos perceber que esse é um conceito artificial. Está presente no discurso de chefias intermediárias, gerências e diretoria, mas, quando se trata do trabalhador comum, administrativo ou da produção, instala-se uma lacuna. Alguns deles não 
têm sequer noção do que seja a cultura da organização, enquanto outros têm compreensão equivocada do conceito.

É comum a simbiose entre os desejos e anseios pessoais de lideranças e aquilo que elas acabam denominando cultura organizacional. Freud (1974, p. 165-166) explica que

a premência que se volta para a felicidade pessoal e a que se dirige para a união com os outros seres humanos devem lutar entre si em todo indivíduo, e assim também os dois processos de desenvolvimento, o individual e o cultural, têm de colocar-se numa oposição hostil um para com o outro e disputar-se mutuamente a posse do terreno. Contudo, essa luta entre o indivíduo e a sociedade não constitui um derivado da contradição - entre os instintos primevos de Eros e da Morte.

A analogia entre o processo civilizatório e o caminho do desenvolvimento individual é passível de ser ampliada sob um aspecto importante. Pode-se afirmar que também a comunidade desenvolve um superego cuja influência se produz na evolução cultural.

Ao perguntarmos a B qual a sua percepção sobre cultura organizacional, ele nos respondeu:

"É uma palavra forte. E cada um tem a sua. Então, com as 120 pessoas, o que é que eu faço. Eu digo: 'Gente, estamos aqui para fazer peças, e peças boas, que deem lucro'. Passamos até doze horas dentro da empresa. Esse é o nosso dia a dia. enquanto ela for bem, nós iremos também. Essa é a cultura que eu procuro passar pro pessoal. E isso está enraizado em algumas áreas, em outras não. Minha cultura e fazer peças, e bem feitas. Se a empresa ganhar dinheiro, eu vou ganhar também."

E, quando perguntamos, na entrevista A, se "alta direção e intermediários falam muito em cultura organizacional, mas o chão de fábrica nem sabe o que é isso", ouvimos:

"Eles seriam os agentes de mudança, mas 'casa de ferreiro, espeto de pau'. Os gerentes trancam, sim, talvez não tanto em nossa empresa, porque nossa mão de obra, ela é bem menor, pelo tipo de processo. Então, a habilidade do operador não influencia tanto no resultado. Então é muito mais fácil você controlar uma máquina. Quanto uma máquina está 'doente', você troca um rolamento, troca o motor, você troca uma chapa, que ela volta a funcionar. Um operador, não adianta você trocar alguma coisa. Então na [nome da organização A1] o pessoal lida com muito com a habilidade do operador e por isso mesmo deveria investir mais na disseminação de uma cultura da empresa."

O que podemos perceber, então, é que aqueles atores organizacionais que deveriam multiplicar os valores culturais funcionam, em muitos casos, como gargalo. E alguns daqueles que se imaginam multiplicadores repassam algu- 
mas percepções pessoais, dissociadas de valores que efetivamente comporiam uma cultura global, complexa, dinâmica, que integre a estratégia da organização. A entrevista C confirmou:

"O que mais tem é boato. É difícil ficar sabendo da voz mesmo da empresa. Só se for uma coisa muito séria. Senão, fica nas coisas que não são muito sérias, nas quais o pessoal só fala por falar." Falaram [em cultura organizacional], mas aquela vez que a gente fez um curso. Ai, eu não sei, explica muito assim. Depois, nunca mais fizeram nada."

\section{CONSIDERAÇÕES FINAIS}

Somos levados a pensar que, normalmente, nas organizações, a comunicação é descendente e racionalizada. Entendemos que ela precisa contemplar aspectos de subjetividade e acontecer, também, na direção inversa: de forma ascendente. Pretendemos com isso dizer que os processos comunicacionais precisam estar geneticamente contaminados por processos relacionais dinâmicos, fluidos, em permanente renovação e computando singularidades.

Parece-nos um equívoco pensar que uma organização consiga "implantar" programas de comunicação como se fossem próteses (que, não esqueçamos, estão sujeitas, evidentemente, a rejeições). Mudanças precisam partir de dentro desse organismo, pressupondo escuta, contemplando a polissemia dos discursos, contemplando o agir recursivamente, ou seja, autoecoalimentando-se de confusões, falhas, brechas, fissuras, ruídos, vencendo suas próprias resistências, o que, sabemos, não é um processo fácil, tampouco imediatista, e pressupõe o engajamento subjetivo de seus integrantes.

Enfraquecer os tentáculos entre poder e cultura, na direção de um saber coletivo; olhar para os sujeitos reconhecendo-os como produtores e não apenas como produtos da organização; vislumbrar o poder em diferentes momentos, lugares, formas, não a partir de um mesmo agente, mas disseminado entre os agentes-sujeitos; tudo isso tenderá ao equilíbrio, mesmo que pela aglutinação/reaglutinação atração/repulsa desses mesmos agentes-sujeitos.

Preferimos nos associar a Freud, quando lembra o homem não trouxe consigo a vocação para o trabalho nos termos em que o modo de produção capitalista o insere na sociedade. Assim, entendemos como importante que as organizações olhem para as relações capital/ trabalho como um dos modos possíveis de o sujeito organizar-se psiquicamente e em termos sociais, como decorrência e fundamento do processo civilizatório, o que precisa incluir não apenas técnica e método, mas também criatividade.

No sentido da consecução do que defendemos, pensamos o trabalho com dois aspectos indissociáveis/complementares: um material e outro simbólico. No 
aspecto material, o relacionamos à sobrevivência, ao sustento, à satisfação de necessidades materiais, enquanto o aspecto simbólico é responsável pela produção de significados, pela constituição de laços sociais, pela autoestima e pela própria transformação do sujeito, passando, também, pela via do afeto e pela própria constituição desse sujeito.

Como jornalista / consultora na área da comunicação organizacional e ao longo de nossa trajetória paralela como estudiosa e pesquisadora na mesma área, e com esta pesquisa especificamente, pudemos perceber que organizações são instituições ${ }^{9}$ cada vez mais presentes no cotidiano social, com ingerência nas esferas social, política e econômica, sem sombra de dúvida.

Essas instituições que, em alguns momentos e modelos de sociedade, chegam a substituir/ocupar o lugar do Estado, já não se contentam com o lugar de aparelhos repressivos ou aparelhos ideológicos; elas os subtraem, invasivas: tentam destituí-lom. Os estudos da comunicação e os estudos da psicanálise não podem, segundo nosso modo de ver, subtrair-se a essa reflexão.

Organizações são instituições a exemplo do que são a escola, a família, o direito... Mas seu poder de barganha, seu agigantamento levam à subversão de uma ordem até aqui vigente. Elas tendem a ocupar o status reservado ao Estado, enquanto as demais, independentemente do arranjo de interesses, estão a serviço da sustentação desse mesmo Estado.

Não podemos esquecer que essas instituições se autoeco-organizam com a ingerência de sujeitos, que, recursivamente, buscam imprimir-lhes suas características (aqui pensamos que características sejam o modo de atuar das suas estruturas psíquicas). E todos sabemos que o sujeito convoca o outro a "entrar no seu sintoma” (dele, sujeito), o que efetivamente introduz a relação.

Pensamos, dessa forma, que seja enriquecedor para o estudo das relações e da comunicação organizacional, amparar-se na psicanálise para refletir sobre / analisar suas questões. Mas, depois do estudo desenvolvido, também despertamos para o fato de que essa relação é circular, ou seja: é fundamental também para a psicanálise preocupar-se com essas instituições, tanto quanto se preocupa com outras, como a família e o casamento, apenas a título de exemplo, à medida que os sujeitos estão nelas enlaçados irrevogavelmente.

O sujeito contemporâneo, cooptado pelo social desde a horda primeva de que falava Freud - conforme abordamos no corpo do trabalho -, já não tem

9 Entendemos instituição na perspectiva de Lebrun (2009, p. 123): “Conjunto das formas ou estruturas fundamentais de organização social, como são estabelecidas pela lei ou pelos costumes. 0 u, no singular, instituição remete ao conjunto das estruturas organizadas tendendo a se perpetuar em cada setor da atividade social: assim é a instituição jurídica, política, artística. [...] Finalmente, instituições também significam a ação de instruir e de formar pela educação ou, mais concretamente, o estabelecimento de educação e de instrução, como a escola ou a academia, por exemplo. Nesse último caso a instituição designa mais o local que acolhe o que ali é instituído. 
como sobreviver/ constituir-se fora dessas instituições, assim como também estas não podem acontecer fora da esfera social. São ambos - sujeitos e instituições - produtores e produto um do outro, mutuamente controlados e controladores, o que delega à comunicação e à psicanálise espaço/papel de importância fundamental.

Pensamos ter respondido as questões que deram início às nossas reflexões. A primeira era: como o comportamento dos sujeitos organizacionais estudados, se considerarmos aspectos psíquicos, pode estar relacionado ao "desenho" das relações dos públicos nas organizações? Essa questão ficou muito bem ilustrada quando diversos dos entrevistados da organização A1 fizeram comentários em relação à personalidade, à forma de ser e de relacionar-se de determinado gerente, responsável pela (injusta na visão dos trabalhadores) demissão de um supervisor. Comentários dos entrevistados mostram que os dois sujeitos (gerente e supervisor) "desenhavam" relações diferentes com a população em questão o que levou, naturalmente, a outro aspecto destacado nessa pesquisa: a disputa de poder e consequente demissão do supervisor.

No que diz respeito à questão sobre "qual o papel dos aspectos psíquicos e de personalidade dos sujeitos das organizações, na 'leitura' que farão, bem como na resposta que darão aos apelos e premissas da cultura das organizações", percebemos que em muitos casos, apesar de ignorados, esses aspectos são de grande importância. Podemos, a título de ilustração, recorrer ao supervisor mencionado em uma das entrevistas, cujo critério essencial para a seleção de trabalhadores para seu setor era serem dóceis, submissos, calados. Temos, com esse exemplo, a perspectiva de quem contrata (chefia/ poder) e a perspectiva de quem é contratado, cuja postura será, evidentemente, a de submissão.

No corpo do trabalho (pesquisa) trouxemos alguns exemplos de como chefias imprimem às relações com os subordinados o seu modo de ser/ver/perceber. Ficaram evidentes situações em que elas convocam o outro a responder ao seu sintoma, assim como ficaram evidentes mecanismos de defesa, grupais e individuais, que os sujeitos acionam ao estabelecer relações. Tornou-se patente, também, principalmente se olharmos para os excertos de algumas das entrevistas, a importância do "não-ouvido" ao lado dos bem-ditos, mal-ditos e não-ditos de que fala Roman (2009).

Com essa pesquisa, buscamos entender como as organizações podem modificar e melhorar os processos comunicacionais, investindo na qualificação dos processos relacionais e se elas consideram os aspectos psíquicos nos processos relacionais com os sujeitos organizacionais estudados. Afirmações categóricas e generalizações amplas são perigosas e, na maioria das vezes, confoeme entendemos, inconvenientes. Neste momento do trabalho e das organizações que acompanhamos, podemos dizer que elas não consideram aspectos psíquicos dos sujeitos organizacionais estudados. Mas percebemos também que os 
dois grupos estão em momentos distintos com relação a esse aspecto, havendo, de parte do grupo B (organização B), mesmo que incipiente e, diríamos, quase mecânico ainda, o desejo de andar nessa direção.

Os objetivos da pesquisa eram: perceber, a partir da análise do grupo de entrevistas colhido, como acontecem os principais processos de comunicação organizacional; analisar se e como elementos de subjetividade dos atores de organizações podem interferir na recepção/interpretação/emissão de mensagens; estudar como esses processos de comunicação poderiam contribuir para a compreensão de aspectos complexos das relações interpessoais e intergrupais na organização; e propor um caminho (entre tantos outros) que propicie repensar os sujeitos organizacionais e a fixidez com que são definidas e analisadas as noções de cultura/cultura organizacional, de ideologia e de poder, intimamente relacionadas entre si e desempenhando papel de sustentação de uma postura paralisante e alienadora.

Entendemos, agora ainda mais, que a escuta seja imprescindível no desenho das relações em qualquer tipo de organização. Um exemplo simples ilustra isso com riqueza: quando um líder com características paranoides convoca seus liderados a entrarem no jogo de uma fantasia de perseguição, o sujeito de seu inconsciente não medirá esforços para que o grupo entre em seu sintoma.

O sujeito do inconsciente de alguns integrantes desse grupo, com certeza, ficará preso ao sintoma desse líder e o próprio grupo poderá desenvolver uma "estrutura/personalidade paranoide", o que levará a problemas de relacionamento/comunicação. Esses problemas poderão vir a ser até mesmo muito mais sérios em relação a(os) integrante(s) do grupo que se recusem a "entrar no sintoma”, à medida poderão ser eleitos "bodes expiatórios" na relação, tanto com o líder quanto com o próprio grupo.

Parece-nos, portanto, fundamental que a organização desenvolva escutas na direção de seus sujeitos / grupos e que ela "faça uma escuta de si" como instituição. Nesse sentido, reiteramos o fato de os dois grupos organizacionais estudados se encontrarem em patamares diferentes na caminhada para a solução do problema aqui abordado.

Encontrar "a" solução para o problema levantado em nossa pesquisa seria incoerente de nossa parte. Pensamos a questão dialética/dialogicamente. Vemos a solução como algo temporário, parcial, à medida que as relações são dinâmicas, se modificam e, pensando nos significantes da psicanálise, deslizam permanentemente. Dessa forma, acreditamos que olhar para a comunicação organizacional em uma transdisciplinaridade comunicação/ psicanálise seja um passo na busca de algumas respostas importantes, mas também na pesquisa de novas questões, essas, sim, mobilizadoras de transformações importantes. 


\section{REFERÊNCIAS}

ALTHUSSER, Louis. Aparelhos ideológicos de Estado. São Paulo: Graal, 2003.

. Ideologia e aparelhos aparelhos ideológicos do Estado. Porto, Portugal: Presença, 1974.

BAUER, Martin; GASKELL, George. Pesquisa qualitativa com texto, imagem e som: um manual prático. Petrópolis: Vozes, 2005.

CAON, José Luiz. Pesquisa psicológica e pesquisa psicanalítica. Mars Gravidus, revista do Laboratório de Psicanálise e Aprendizagem da UFRGS, Porto Alegre, a. 1, n. 1, [s. p.], 2002.

. Tradição ou pesquisa. In: COUTO, Luís Flávio Silva (Org). Pesquisa em psicanálise. Rio de Janeiro: Associação Nacional de Pesquisa e Pós-graduação em Psicologia, 1996. p. 93-108.

CHARAUDEAU, Patrick; MAINGUENEAU, Dominique. Dicionário de análise do discurso. São Paulo: Contexto, 2006.

DEJOURS, Christophe. A banalização da injustiça social. 7. ed. Rio de Janeiro: Editora FGV, 2006.

. A loucura do trabalho. 4. ed. Perdizes: Cortez, 2005.

DOR, Joel. 0 pai e sua função em psicanálise. Rio de Janeiro: J. Zahar, 1993.

ENRIQUEZ, Eugène. A organização em análise. Petrópolis: Vozes, 1997.

FOUCAULT, Michel. Microfísica do poder. 17 ed. Rio de Janeiro: Graal, 2003.

. Arqueologia do saber. Rio de Janeiro: Forense Universitária, 1997.

. Vigiar e punir. Petrópolis: Vozes, 1987.

FREUD, Sigmund. Edição standard brasileira das obras psicológicas completas de Sigmund Freud. Vol. XXI.Rio de Janeiro: Imago, 1974.

GASKELL, George. Entrevistas individuais e grupais. In: BAUER, Martin; GASKELL, George. Pesquisa qualitativa com texto, imagem e som: um manual prático. Petrópolis: Vozes, 2005.

GILL, Rosalind. Análise de discurso. In: BAUER, Martin; GASKELL, George. Pesquisa qualitativa com texto, imagem e som. 4. ed., Petrópolis: Vozes, 2005.

GOLDENBERG, Mirian. A arte de pesquisar: como fazer pesquisa qualitativa em ciências sociais. 3. ed. Rio de Janeiro: Record, 1999.

HAGUETTE, Teresa M. Frota. Metodologias qualitativas na sociologia. 3. ed. Petrópolis: Vozes, 1992.

IRIBARRY, Isaac Nikos. 0 que é pesquisa psicanalítica. Ágora - Estudos em Teoria Psicanalítica, Rio de Janeiro, v. IV, n. 1, p. 115-138, jan./jun. 2003.

LACAN, Jacques. Meu ensino. Rio de Janeiro: Zahar, 2006.

LEBRUN, Jean-Pierre. Clínica da instituição: o que a psicanálise contribui para a vida coletiva. Porto Alegre: CMC, 2009.

MORAES, Roque; GALIAZZI, Maria do Carmo. Análise textual discursiva. ljuí, RS: Unijuí, 2007.

MORIN, Edgar. Os sete saberes necessários à educação do futuro. São Paulo: Cortez, 2001 a.

. 0 método - 2: a vida da vida. Porto Alegre: Sulina, 2001b.

ROMAN, Artur Romero. Organizações: um universo de discursos bem-ditos, mal-ditos e não-ditos. In: KUNSCH, Margarida M. Krohling (Org.). Comunicação Oganizacional. Vol. 1. linguagem, gestão e perspectivas. São Paulo: Saraiva, 2009.

SóLIO Marlene Branca. Jornalismo organizacional: produção e recepção. Caxias do Sul, RS: Educs, 2008.

Recebido em: 25.09.2009 / Aceito em: 22.02.2010 